\title{
Review \\ Evolving Paradigms in the Systemic Treatment of Advanced Gallbladder Cancer: Updates in Year 2022
}

\author{
Zishuo Ian Hu and Kian-Huat Lim *(D)
}

Citation: Hu, Z.I.; Lim, K.-H. Evolving Paradigms in the Systemic Treatment of Advanced Gallbladder Cancer: Updates in Year 2022. Cancers 2022, 14, 1249. https:// doi.org/10.3390/cancers14051249

Academic Editor: David Wong

Received: 23 January 2022

Accepted: 25 February 2022

Published: 28 February 2022

Publisher's Note: MDPI stays neutral with regard to jurisdictional claims in published maps and institutional affiliations.

Copyright: (C) 2022 by the authors. Licensee MDPI, Basel, Switzerland. This article is an open access article distributed under the terms and conditions of the Creative Commons Attribution (CC BY) license (https:// creativecommons.org/licenses/by/ $4.0 /)$.

\author{
Division of Oncology, Department of Internal Medicine, Barnes-Jewish Hospital and The Alvin J. Siteman \\ Comprehensive Cancer Center, Washington University School of Medicine, St. Louis, MO 63110, USA; \\ huzi@wustl.edu \\ * Correspondence: kian-huat.lim@wustl.edu; Tel.: +1-314-747-7510
}

Simple Summary: Gallbladder cancer is distinct type of biliart tract cancer that is rare, aggressive and with limited treatment options aside from surgical resection. As of now in year 2022, systemic chemotherapy remains as the mainstay treatment option for patients with advanced staged gallbladder cancer. Despite decades of scientific research, new treatment options have been struggling to succeed. Furthermore, almost all clinical studies on gallbladder cancer have included other tyes of biliary tract cancers, raising the need to specifically inspect the outcomes of these clinical trial regimens on gallbladder cancer. In this article, we summarized all seminal literature and the most recent advances in scientific discoveries and clinical trials on gallbladder cancer. We provide a succinct update on current understanding, treatment landscape and therapeutic challenges in gallbladder cancer, as well as future prospects in the management of this disease.

\begin{abstract}
Gallbladder cancer (GBC) is a biological, anatomical, and clinically distinct subset of biliary tract cancers (BTC), which also include extra- and intra-hepatic cholangiocarcinoma. The advent of next-generation sequencing (NGS) clearly shows that GBC is genetically different from cholangiocarcinoma. Although GBC is a relatively rare cancer, it is highly aggressive and carries a grave prognosis. To date, complete surgical resection remains the only path for cure but is limited to patients with early-stage disease. The majority of the patients are diagnosed at an advanced, inoperable stage when systemic treatment is administered as an attempt to enable surgery or for palliation. Gemcitabine and platinum-based chemotherapies have been the main treatment modality for unresectable, locally advanced, and metastatic gallbladder cancer. However, over the past decade, the treatment paradigm has evolved. These include the introduction of newer chemotherapeutic strategies after progression on frontline chemotherapy, incorporation of targeted therapeutics towards driver mutations of genes including HER2, FGFR, BRAF, as well as approaches to unleash host antitumor immunity using immune checkpoint inhibitors. Notably, due to the rarity of BTC in general, most clinical trials included both GBC and cholangiocarcinomas. Here, we provide a review on the pathogenesis of GBC, past and current systemic treatment options focusing specifically on GBC, clinical trials tailored towards its genetic mutations, and emerging treatment strategies based on promising recent clinical studies.
\end{abstract}

Keywords: gallbladder cancer; GemCis; HER2; FGFR; PD-L1; immunotherapy

\section{Introduction}

Gallbladder cancer (GBC) is a rare but deadly malignancy, with an estimated 5-year survival rate of $2 \%$ in metastatic disease. Prognosis is particularly poor in older patients and racial minorities [1]. Worldwide, the incidence of GBC varies significantly based on geographic location. Incidence rates are very high in South America, high in Japan and Korea, moderate in Eastern and Central Europe, and low in North America. In the United States, GBC is a relatively rare cancer. In 2022, an estimated 12,130 GBC and other 
biliary cancers are expected to be diagnosed, and 4400 will die from these diseases [2]. Here we review the risk factors for developing GBC, its pathophysiology, current systemic treatments, and ongoing clinical trials with a focus on targeted therapy for GBCs.

\section{Risk Factors}

In addition to ethnicity, a host of other risk factors have been implicated in the development of GBC, including existing cholelithiasis, gender, older age, obesity, occupation, Salmonella infection, and genetic predisposition. In the United States, American Indian and Hispanic women have the highest incidence and mortality rates of GBC [3]. In more recent years, there has also been an increase in GBC incidence rates in the African American population [4]. Gallstones are found in $69-86 \%$ of all GBC patients and have been strongly associated with GBC [5-8]. However, the incidence of GBC in patients with gallstones was reported to be 0.5 , and the majority of patients with gallstones will not develop gallbladder cancer in their lifetimes [9]. Older age is associated with GBC, with a median age of 67-72 years [10-12]. Women are two to six times more likely to develop GBC than men [11]. Obesity and occupation in the textile, chemical processing, and petroleum refining industries have also been linked to GBC [13-17]. In Salmonella-endemic regions of the world, such as the Indian subcontinent and central and South America, the chronic infection has been linked to GBC $[18,19]$. Patients with Lynch syndrome were also reported to be at a higher risk of developing GBC [20].

\section{Pathogenesis}

The pathogenesis of GBC is thought to derive largely from chronic inflammation. The current gallbladder carcinogenesis model postulates that chronic inflammation of the gallbladder leads to hyperplasia and metaplasia, which can develop into dysplasia, then in situ carcinoma, and eventually invasive carcinoma in a step-wise fashion [21,22]. Roa et al., used mapping techniques on gallbladders with invasive cancers and found that metaplasia, dysplasia, and carcinoma in situ were adjacent to cancer in $66 \%, 81.3 \%$, and $69 \%$ of the cases, respectively $[23,24]$.

The exact etiology of chronic inflammation of the gallbladder varies by ethnicity. Chronic inflammation brought on by gallstones promotes a pro-carcinogenic microenvironment, stimulating tumor proliferation and progression [25]. GBC in South America has largely been attributed to chronic inflammation from gallstones. Twenty-seven percent of the adult population in Chile are estimated to have gallstones, and Chile has one of the highest rates of GBCs in the world, with an estimated 9.2 cases per 100,000 [26,27]. Indigenous Chilean Mapuche Indian women, in particular, have very high rates of gallstone prevalence and mortality [28,29]. The Chile Biliary Longitudinal Study (Chile BiLS) is a study of 4726 Chilean women with gallstones enrolled from 2016 to 2019 that are being followed for gallbladder dysplasia or cancer for six years [30]. Analysis of the inflammatory profile of 200 Mapuche women with gallstones in the BiLS study found that they expressed higher levels of the inflammatory cytokine IL-8 compared to 200 non-Mapuche women with gallstones, suggesting that there may be ethnic differences in the inflammatory response to gallstones [31].

In Japan and China, a series of studies also reported an association between GBCs and anomalous pancreaticobiliary ductal junction (APDJ), a rare congenital anomaly [32-36]. Patients with APDJs experience chronic reflux of pancreatic juice into the bile duct, causing chronic inflammation in the biliary tract, which can eventually lead to hyperplasia, metaplasia, and cancer of the bile ducts. A meta-analysis of nine case-control studies found that the incidence of APDJ was higher in GBC patients than in control patients $(10.60 \%$ vs. 1.76\%, OR: $7.41,95 \%$ CI: 5.03 to $10.87, p<0.00001$ ) [37].

\section{Genomics}

Genomic sequencing has revealed significant heterogeneity in genes commonly mutated in biliary tract cancers (BTCs). Mutations in FGFR1, FGFR2, IDH1, IDH2, BAP1, and 
ARID1A are more commonly found in intrahepatic cholangiocarcinoma, while SMAD4 mutations are more commonly seen in extrahepatic cholangiocarcinomas [38-42].

GBCs are molecularly distinct from other BTCs. A number of studies have reported increased activation of the EGFR family of genes in GBCs [42-44]. Other genetic mutations found to be associated with GBC include TP53, SMAD4, ARID1A, PIK3CA, CDKN2A, and CDKN2B [42,44-47]. Weinberg et al., reviewed 1502 BTCs using next-generation sequencing (NGS), immunohistochemistry, in situ hybridization, and RNA sequencing and found that GBCs had significantly higher Her2/neu overexpression (9.2\%) and amplification (1.44\%) and high TOP2A expression (78.3\%) and amplification (25\%) compared to cholangiocarcinomas [44]. The authors also found that $19.1 \%$ of 428 GBCs had mutations in homologous repair genes.

There was also some evidence that GBC tumor mutations vary depending on geographic location [48]. Narayan et al., reviewed 81 patients globally, with 21 patients from Chile and 11 patients from Japan [48]. They found that several mutations were notably absent in specific populations. ARID1A and PIK3CA mutations were not present in the Japanese cohort. ARID2 and ERBB3 mutations were absent in Chilean patients.

It is unclear whether HER2/neu overexpression is associated with worse survival in GBCs. Based on a retrospective evaluation by Vivaldi et al., HER2 overexpression was associated with lower 5-year overall survival (OS, $34 \%$ vs. $41 \%$ ) and shorter disease-free survival (DFS, 10.6 vs. 20.9 months) compared to HER2-negative BTCs [49]. Although it is difficult to extrapolate this result to GBCs in particular since 12 of the 13 GBC patients in the study were HER2 negative. Roa et al., performed immunohistochemistry in 187 cases of GBCs and also found that HER2/neu was overexpressed in $12.8 \%$ of cases but did not find a statistically significant difference in OS at 5 years between HER2 positive and HER2 negative cases [43]. The molecular pathogenesis of GBCs may also be attributed to two different genetic pathways. In GBCs arising from APDJs, KRAS mutations are common, and TP53 mutations are relatively late onset [50-52]. In GBCs of Chilean patients with cholelithiasis, KRAS mutations are rare, and TP53 mutations are more common [53,54].

\section{Treatment Options}

Developing effective treatment options for GBC has been relatively challenging, given the rarity and aggressiveness of the disease. As a result, despite having different risk factors and profiles, all BTCs, including intrahepatic cholangiocarcinoma, extrahepatic cholangiocarcinoma, and GBC, were often grouped together in large phase 3 clinical trials.

\subsection{Neoadjuvant Therapy for BTCs}

There is currently no preferred neoadjuvant therapy for gallbladder cancer. There is relatively limited data to support a standard regimen or definitive benefit currently. A retrospective review of 74 GBC patients by Creasy et al., found a subset of patients that responded to neoadjuvant therapy and had improved outcomes after definitive surgery [55]. Shroff et al., evaluated the use of gemcitabine, cisplatin, and nab-paclitaxel in 60 patients with advanced BTCs in a phase 2 study [56]. Thirteen of the patients had GBC. ORR was $45 \%$, and the disease control rate was $84 \%$. Notably, 12 patients were converted from unresectable to resectable disease and underwent surgery. Other chemotherapy options for neoadjuvant therapy include single-agent 5-FU, single-agent capecitabine, single-agent gemcitabine, a gemcitabine-platinum combination, or a 5-FU-platinum combination.

\subsection{Adjuvant Therapy}

Surgery remains the only curative option for GBC. Despite curative resection, $66 \%$ of patients with GBC were reported to develop disease recurrence within 2 years, often at a distant site [57]. Although there is currently no established neoadjuvant therapy for BTCs, a few clinical trials have been reported recently for adjuvant therapy in BTCs (Table 1). 
Table 1. Current adjuvant options after surgical resection of GBC.

\begin{tabular}{lllll}
\hline Authors & Phase & Treatment & Median RFS (Months) & Median OS (Months) \\
\hline $\begin{array}{l}\text { Primrose [58] } \\
\text { BILCAP study }\end{array}$ & 3 & capecitabine vs. observation & 24.4 vs. 17.5 ( $p=0.03)$ & 51.1 vs. 36.4 (p=0.097) \\
\hline $\begin{array}{l}\text { Edeline [59] } \\
\begin{array}{l}\text { PRODIGE 12-ACCORD } \\
18 \text { study }\end{array}\end{array}$ & 3 & GEMOX vs. observation & 30.4 vs. 18.5 ( $p=0.48)$ & 75.8 vs. 50.8 (p=0.74) \\
\hline $\begin{array}{l}\text { Ben-Josef [60] } \\
\text { SWOG S0809 study }\end{array}$ & 2 & $\begin{array}{l}\text { Gemcitabine and capecitabine } \\
\text { followed by capecitabine with } \\
\text { RT }\end{array}$ & 26 & 35 \\
\hline
\end{tabular}

The BILCAP study was a phase 3, randomized multi-institutional study conducted in the United Kingdom that compared capecitabine to observation in patients that had cholangiocarcinoma or GBC who had undergone a macroscopically complete resection with curative intent [58]. Four hundred and forty-seven patients were enrolled over the course of 2006 and 2014. Seventy-nine GBC patients were in the study. There was no statistically significant improvement in OS with the capecitabine group in the intention-to-treat (ITT) analysis (median 51.1 versus 36.4 months, hazard ratio $0.81,95 \%$ CI $0.63-1.04 ; p=0.097$ ). However, after sensitivity analysis in the ITT population, which adjusted for minimization factors, nodal status, grade, and gender, the HR for OS was $0.71(95 \% \mathrm{CI}, 0.55-0.92 ; p=0.01)$. Based on the findings of this study, current NCCN guidelines recommend 6 months of adjuvant capecitabine for resected GBC.

The PRODIGE-12/ACCORD-18 study was a phase 3, randomized multi-institutional French study that compared gemcitabine and oxaliplatin (GEMOX) to observation in patients with cholangiocarcinoma or GBC who had undergone a macroscopically complete resection with curative intent [59]. They recruited 196 patients from 2006 to 2014. There were $38 \mathrm{GBC}$ patients in the study. After a median follow-up of 46.5 months, the study investigators found no difference in median OS between the GEMOX group vs. the observation group (75.8 months vs. 50.8 months, HR $0.71,95 \%$ CI $0.70-1.66, p=0.74$ ). Planned subgroup analyses of the GBCs, ECC, and ICC did not suggest any subgroup that benefited from adjuvant GEMOX. There was actually worse recurrence-free survival (RFS, $p=0.034)$ and OS $(p=0.017)$ in GBC patients that received GEMOX.

SWOG S0809 is a phase II trial that assessed adjuvant capecitabine and gemcitabine followed by concurrent capecitabine-based chemoradiation after resection of ECC and GBC. A total of 79 patients (68\% ECC and 32\% GBC) were treated. For all patients, 2-year survival for all patients was $65 \%$ (95\% CI $53 \%$ to $74 \%$; $68 \%$ for ECC and $56 \%$ for GBC, $p=0.87$ ). Median OS was 35 months and did not differ between R0 and R1 resections. Interestingly, the first relapse occurred predominantly at distant sites in GBC patients, potentially suggesting the effectiveness of local control for a combined-modality regimen.

\subsection{Systemic Therapy}

Cytotoxic chemotherapy remains the mainstay treatment for patients with inoperable GBC (Table 2). The ABC-02 trial was a phase 3, randomized study that compared gemcitabine plus cisplatin (GemCis) to gemcitabine alone in 410 patients with locally advanced or metastatic cholangiocarcinoma, gallbladder cancer, or ampullary cancer [61]. Median OS was 11.7 months in the GemCis group and 8.1 months in the gemcitabine group (HR 0.64, $95 \%$ CI 0.52 to $0.80 ; p<0.001)$. PFS was 8.0 months in the GemCis group and 5.0 months in the gemcitabine group (HR $0.63,95 \%$ CI 0.51 to $0.77 ; p<0.00$ ). Tumor control was $81.4 \%$ in GemCis group and $71.8 \%$ in the gemcitabine group $(p=0.049)$. Importantly, subgroup analysis showed that the benefit of GemCis was comparable among patients with GBC, ICC, or ECC (HR of 0.61, 0.57, and 0.73, respectively). Based on the results of this study, gemcitabine with cisplatin has been the first-line therapy for locally advanced and metastatic BTC since at least the year 2010. 
Building on this regimen, a phase 2 trial that included 60 patients, nab-paclitaxel plus GemCis, resulted in a median PFS of 11.8 months and a median OS of 19.2 months in an intention-to-treat analysis. The partial response rate was $45 \%$, and the disease control rate was $84 \%$ [56]. However, due to significant hematologic toxicities from the first 32 enrolled patients, the starting dose of each agent had to be reduced in the remaining patients. A phase III randomized trial of gemcitabine, cisplatin, and nab-paclitaxel versus gemcitabine and cisplatin in newly diagnosed, advanced BTCs (SWOG S1815, NCT03768414) has recently completed accrual, and the results are eagerly awaited. However, it is likely that the triplet regimen will be associated with more side effects and should be offered to highly selected patients with good performance status and organ functions. Due to the higher partial response rate, there is currently high interest in testing this chemotherapy triplet as a neoadjuvant downstaging strategy for patients with initially unresectable GBCs or GBC with high-risk features such as a bulky tumor, liver invasion, and multiple enlarged adjacent lymph nodes.

FOLFOX as second-line therapy for BTC was established by the recently reported ABC06 trial [62]. The ABC-06 trial was a phase 3, randomized study that compared FOLFOX with active symptom control (ASC) to ASC alone in 162 locally advanced or metastatic BTC patients who had progressed on GemCis. Thirty-four GBC patients were included in the study. For all BTC patients, median OS was significantly longer in the FOLFOX group (6.2 months) compared to the ASC alone group (5.3 months) (HR 0.69, 95\% CI 0.50$0.97 ; p=0.031$ ) at 6 months. After 1 year, the OS rate was $25.9 \%$ in the FOLFOX group and $11.4 \%$ in the ASC alone group. The objective response rate was $5 \%$ in the FOLFOX group. However, it is worth noting, in the GBC subgroup specifically, median OS in the FOLFOX group was 5.1 months compared to 4.6 months in the ASC alone group (HR of $0.56,95 \%$ CI 0.27-1.17).

Besides FOLFOX, the combination of 5-FU/leucovorin and liposomal irinotecan as second-line treatment is another option. In a multicenter, open-label, randomized, phase $2 \mathrm{~b}$ study performed in South Korea (NIFTY), 174 patients were enrolled (88 treated with liposomal irinotecan plus 5-FU/leucovorin, and 86 in the 5-FU/leucovorin group). At a median follow-up of 11.8 months, the median PFS was significantly longer in the liposomal irinotecan plus 5-FU/leucovorin group (7.1 months, 95\% CI 3.6-8.8) compared to 5-FU/leucovorin group (1.4 months, 1.2-1.5; hazard ratio 0.56 , 95\% CI 0.39-0.81; $p=0.0019)$ [63]. As expected, patients treated with liposomal irinotecan plus 5-FU/LV experienced more side effects, including neutropenia and fatigue. A similar study testing liposomal irinotecan plus 5-FU/LV for biliary cancer is being evaluated in a phase 2 study in the US (NAPOLI-2, NCT04005339).

Table 2. Current systemic options for advanced, inoperable GBC.

\begin{tabular}{llllll}
\hline Authors & Phase & Line of Treatment & Treatment & Median PFS \\
(Months)
\end{tabular}

Abbreviations: GEMCIS = gemcitabine plus cisplatin. GEMOX = gemcitabine plus oxaliplatin. CAPOX = capecitabine plus oxaliplatin. $\mathrm{CT}=$ chemotherapy. $\mathrm{RT}=$ radiotherapy. $\mathrm{CRT}=$ chemoradiotherapy. 


\section{Targeted Therapy}

Although cytotoxic chemotherapy currently remains the mainstay for adjuvant and advanced GBC, the advent of next-generation sequencing has revealed a number of driver mutations in GBC, to which targeted approaches were tested and shown promise in selected patients. Here, we discuss results from clinical trials targeting the HER2, FGFR, BRAF/MEK, and PD-1 pathways (Figure 1) [66-71]. IDH-1 mutations are extremely rare in GBC and more common in ICC and ECC and will not be discussed here.

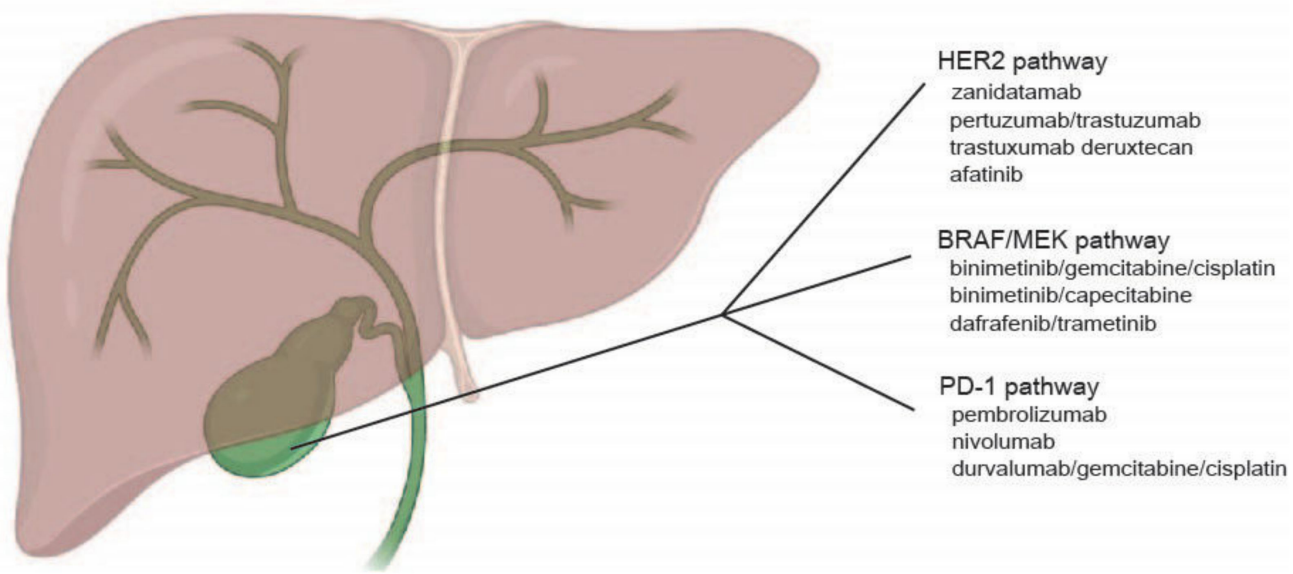

Figure 1. Current therapeutic targets in gallbladder cancer.

\subsection{HER2/neu Pathway}

Mutations or overexpression of HER2/neu are present in 12-15\% of GBC [43]. A number of clinical trials were undertaken to explore the use of HER2/neu-directed therapy in BTCs with mixed results. Two phase 2 trials, by Peck et al., and Ramanthan et al., were conducted with lapatinib tosilate in unselected patients with BTCs, which reported a lack of activity [72,73]. Of the eight evaluable patients treated with lapatinib in Peck et al.'s study, there were no objective responses, and no HER2/neu somatic mutations or HER2/neu overexpression were found. Ramanthan et al., enrolled five GBC patients and found no objective responses to lapatinib. TreeTopp was a randomized phase 2 study of varlitinib, a small molecule pan-human HER inhibitor, with capecitabine compared to capecitabine alone in second-line advanced or metastatic BTC [74]. One hundred and twenty-seven unselected patients were randomized, including 34 GBC patients. PFS was similar for patients receiving varlitnib with capecitabine compared to capecitabine alone. ORR was $9.4 \%$ in the varlitinib with capecitabine group, but not statistically significant from the $4.8 \%$ in the capecitabine alone group $(p=0.42)$.

MyPathway was a multicenter, open-label, phase $2 a$, basket study that evaluated the use of pertuzumab with trastuzumab in patients with previously treated metastatic BTCs with HER2 amplification or HER2 overexpression [75]. ORR was 23\% in 39 enrolled patients. PFS was 4 months, and OS was 10.9 months. Post-hoc, exploratory analysis of the GBC subgroup found an ORR of $31 \%$ in 16 patients and an OS of 14.2 months. These results in MyPathway for metastatic, previously treated GBC patients compare favorably against the results from the ABC-06 trial, where OS was 5.1 months. Notably, this regimen is anticipated to be better tolerated than standard GemCis and should be tested in a randomized study in the future for this population.

Zanidatamab is a bispecific HER2-targeted antibody directed against the juxtamembrane domain (ECD4) and the dimerization domain (ECD2) of HER2. Twenty-one BTC patients (12 GBCs) were enrolled in the expansion cohort of a phase 1 study (NCT02892123) enrolling advanced HER2-expressing cancers with progression after standard of care therapy [76]. The objective response rate was $40 \%$, and the duration of response was 7.4 months. Based on these promising results, HERIZON-BTC-01 is an ongoing, multicenter, open-label phase 2 trial to evaluate zanidatamab in advanced BTCs. 
Harding et al., recently reported on the results of a phase 2 basket trial targeting HER2-mutated advanced BTCs with neratinib [77]. Twenty-five patients with BTCs were enrolled (10 GBCs). ORR was 16\% with an OS of 5.4 months and PFS of 2.8 months. Other ongoing clinical trials include the HERB trial, a multicenter phase 2 study of trastuzumab deruxtecan for HER2-positive unresectable or recurrent biliary cancer [78], and a phase $1 / \mathrm{b}$ study of afatinib in combination with capecitabine in patients with refractory solid tumors [79].

Besides overexpression, activating mutations of HER2/neu, particularly at codon 310 from serine to tyrosine or phenylalanine (S310Y/F), are detected in GBCs. In a multihistology, open-label, phase II 'basket' study (SUMMIT, NCT01953926), neratinib $240 \mathrm{mg}$ daily was tested in patients with somatic HER2 mutations. As of September 2022, 25 patients with HER2-mutant BTC have enrolled: gallbladder (40\%), intrahepatic (24\%), extrahepatic $(20 \%)$, and ampulla of Vater (16\%). Confirmed ORR in these 25 patients was $12 \%(95 \%$ CI 3-31\%). Median PFS and OS were 2.8 (95\% CI 1.1-3.7) and 5.4 (95\% CI 3.7-11.7) months, respectively [77].

Overall, targeting HER2/neu is an active field in GBC with multiple available therapeutic agents. Combination strategies with systemic chemotherapy such as GemCis in carefully designed trials will likely be the next stage of the investigation.

\subsection{FGFR Pathway}

FGFR mutations or fusions are found in about $20 \%$ of intrahepatic cholangiocarcinomas but are relatively rare in extrahepatic cholangiocarcinomas and GBCs ( 3\%) [80]. One current trial investigating FGFR inhibitors in GBC is PUMCH (NCT04211168), a phase 2, single-center trial in China that is testing the use of toripalimab, a PD-1 inhibitor, with lenvatinib, a multi-kinase inhibitor of FGFR, VEGFR, and PDGFR as second-line treatment in BTCs. NCT04742959 is another a phase I clinical trial testing the use of TT-00420, a spectrum-selective multi-kinase inhibitor in patients with advanced solid tumors [81].

\subsection{BRAF/MEK Pathway}

The Raf/MEK/ERK pathway was reported to be activated in BTCs, with BRAF V600E mutations reported in up to $3 \%$ of BTCs [82]. The phase $1 \mathrm{~b}$ ABC- 04 trial examined the combination of selumetinib, a MEK inhibitor, in combination with GemCis in advanced BTCs [83]. They found that two out of eight evaluable patients had a partial or complete response. Binimetinib, another MEK inhibitor, was also tested in combination with GemCis and with capecitabine for patients with BTCs in small phase $1 / 2$ trials [84,85]. Thirtyfour patients with BTC that progressed on gemcitabine-based first-line therapy received binimetinib and capecitabine and had an ORR of $20.6 \%$ with a PFS of 4.1 months and OS of 7.8 months. Thirty-five treatment-naïve BTC patients that received binimetinib with GemCis had an ORR of $36 \%$, PFS of 6 months, and OS of 13.3 months. The ROAR basket trial is a phase 2, open-label trial enrolling patients with recurrent or progressive $B R A F$ V600E mutated cancers $[86,87]$. Forty-three patients with BTCs received dabrafenib, a BRAF inhibitor, and trametinib, a MEK inhibitor. The majority of patients had intrahepatic bile duct cancer, but one patient had GBC. ORR was 47\% (95\% CI, 31-62) and PFS was 9 months (95\% CI, 5-10), and median OS was 14 months (95\% CI, 10-33).

\subsection{PD-1 Pathway}

Immunotherapy for solid tumors has garnered enormous success over the past decade, with immune checkpoint inhibitors targeting the PD-1 and CTLA-4 pathways demonstrating improved OS and response rates compared to standard treatments. Pembrolizumab and nivolumab are anti-PD-1 monoclonal antibodies that have shown activity in tumors with mismatch repair deficiency (MMR-D), high tumor mutation burden (TMB), or PD-L1 expressing tumors. MMR-D ( 3\%) and high TMB cases are rare in BTCs [88], potentially explaining why monotherapy with PD-1 inhibitors has resulted in mixed success. 
Piha-Paul presented data from 104 patients with advanced BTCs from the KEYNOTE158 trial, which treated patients with advanced cancers with pembrolizumab [89]. With a median follow-up of 7.5 months, ORR was $5.8 \%$, with the median duration of response not reached. Median OS was 7.4 months (95\% CI, 5.5-9.6), and median PFS was 2.0 months (95\% CI, 1.9-2.1).

A phase 2 trial investigated the efficacy of nivolumab in patients with advanced BTC refractory to first-line therapy [90]. Of the 54 enrolled patients, 17 patients were GBCs. Objective response was observed in 2 of 13 (15\%) evaluable patients with GBC.

TOPAZ-1 is a randomized, double-blind placebo-controlled, international phase III study combining durvalumab or placebo with GemCis for patients with treatment-naive advanced BTCs [91]. In this study, patients were treated with GemCis plus durvalumab or placebo every 3 weeks for eight cycles, followed by durvalumab or placebo every 4 weeks until disease progression. At data cutoff in August 2021 and presented in the Annual ASCO GI Cancer Symposium that at data cutoff in August 2021 for interim analysis, 685 pts were randomized to durvalumab $+\operatorname{GemCis}(n=341)$ or placebo + GemCis $(n=344)$. The primary objective was met with durvalumab + GemCis significantly improving median OS compared to placebo + GemCis (12.8 vs. 11.5 months, hazard ratio $0.80 ; 95 \%$ confidence interval $0.66-0.97 ; p=0.021)$. PFS was also significantly improved with durvalumab vs. placebo (HR, 0.75; 95\% CI, 0.64-0.89; $p=0.001)$. ORR was $26.7 \%$ with durvalumab and $18.7 \%$ with placebo. Grade 3/4 treatment-related adverse events (TRAEs) were comparable between the two arms [92]. Interestingly, separation of both the PFS and OS curves between the two groups appeared to occur after chemotherapy was completed, raising the question of the benefit of durvalumab when chemotherapy was concurrently administered. Subgroup analysis also showed that Asian patients derived the most benefit from the triple combination than non-Asian patients. The triple combination also seemed to mainly benefit patients with ICC and ECC (HR 0.76 for both) as opposed to GBC (HR 0.94). In addition, the triple combination also appeared to be more beneficial for patients who had recurrent rather than initially unresectable disease and locally advanced versus metastatic disease. Interestingly, the benefit of durvalumab was observed regardless of PD-L1 expression by immunohistochemistry (cutoff of 1\%) in the tumor, immune cells, or total tumor area. Final publication of this study should be available in year 2022. Nonetheless, this study raised significant interest and questions targeting specifically non-Asian and GBC patients which should be further addressed in future trials.

\section{Future Directions}

Multiple trials are ongoing exploring the use of immunotherapy, targeted therapy, and cytotoxic therapy for BTCs. A list of ongoing clinical trials targeting GBCs internationally is listed in Table 3. However, lessons from the recent exciting trials clearly highlighted two areas that need to be worked on to improve the outcomes of GBC patients. First, genomic analysis and clinical trial experience clearly showed that targeting the HER2 pathway is the leading strategy for GBC. Second, the lack of efficacy of lapatinib or vartilinib, as opposed to pertuzumab with trastuzumab or zanidatamab suggest that additional mechanisms of action, such as antibody-dependent cellular toxicity, immune-mediated killing, or direct cytotoxicity provided by chemotherapy may be needed to augment the effect of HER2 inhibition in order to achieve a meaningful clinical response. To this end, combination strategies or newer, more potent HER2-targeted agents such as antibody-drug conjugates should be tested. The promise of immunotherapy, though slightly disappointing based on the subgroup analysis from the TOPAZ-1 study, should warrant more basic translational research into GBC. In particular, PD-1 is only one of the many checkpoint mechanisms that silence anti-tumor T cells. Other checkpoints such as LAG3, TIM3, and TIGIT have all been implicated in T cell exhaustion and remain to be targeted. Furthermore, strategies to overcome additional known biological barriers, including tumor desmoplasia and suppressive myeloid cells in the tumor microenvironment, need to be developed and tested in future trial regimens. The positive results of the TOPAZ-1 study, while exciting 
as this was the first positive trial since $\mathrm{ABC}-02$, are far from being optimal given the mild improvement of median OS from 11.5 to 12.8 months $(p=0.021)$. The plateauing of OS curve after two years for patients treated with durvalumab strongly suggest a need to develop better predictive markers, other than PD-L1 expression by immunohistochemistry, to identify the subgroup of patients who will benefit from checkpoint immunotherapy.

Table 3. Ongoing clinical trials for GBC.

\begin{tabular}{|c|c|c|c|c|c|}
\hline Phase & NCT Number & Tumor Type & Line & Treatment & Location \\
\hline $2 / 3$ & NCT02867865 & $\begin{array}{l}\text { Locally advanced } \\
\text { gallbladder cancers }\end{array}$ & 1st & $\begin{array}{l}\text { Neoadjuvant GEMCIS vs. } \\
\text { neoadjuvant radiation with } \\
\text { weekly gemcitabine }\end{array}$ & India \\
\hline $2 / 3$ & NCT04559139 & $\begin{array}{l}\text { Stage II-III gallbladder } \\
\text { cancers }\end{array}$ & 1 st & $\begin{array}{l}\text { Neoadjuvant GEMCIS, } \\
\text { resection then adjuvant } \\
\text { GEMCIS vs. resection then } \\
\text { adjuvant GEMCIS }\end{array}$ & United States \\
\hline 2 & NCT04333927 & $\begin{array}{l}\text { Resected extrahepatic } \\
\text { cholangiocarcinoma and } \\
\text { gallbladder cancers }\end{array}$ & $1 \mathrm{st}$ & $\begin{array}{l}\text { Camrelizumab, then } \\
\text { capecitabine with } \\
\text { radiotherapy vs. observation }\end{array}$ & China \\
\hline 1 & NCT03257761 & $\begin{array}{l}\text { Unresectable liver, } \\
\text { pancreatic, BTCs }\end{array}$ & 2nd & $\begin{array}{l}\text { Guadecitabine and } \\
\text { durvalumab }\end{array}$ & United States \\
\hline 3 & NCT03673072 & BTCs & 1 st & $\begin{array}{l}\text { Neoadjuvant GEMCIS } \\
\text { followed by liver resection vs. } \\
\text { upfront liver resection }\end{array}$ & Germany \\
\hline 2 & NCT03833661 & Locally advanced BTCs & 2nd & $\begin{array}{l}\text { bintrafusp alfa, a bifunctional } \\
\text { anti-PD-L1/TGF } \beta \text { trap }\end{array}$ & $\begin{array}{l}\text { United States, } \\
\text { Europe, Asia }\end{array}$ \\
\hline 2 & NCT03473574 & Unresectable BTCs & 1 st & $\begin{array}{l}\text { durvalumab/tremelimumab/ge } \\
\text { vs. durval- } \\
\text { umab/tremeliumab/GEMCIS } \\
\text { vs. GEMCIS vs. } \\
\text { durvalumab/GEMCIS }\end{array}$ & $\begin{array}{l}\text { mcitabine } \\
\text { Germany }\end{array}$ \\
\hline 2 & NCT03043547 & Locally advanced BTCs & 2nd & $\begin{array}{l}\text { Liposomal irinotecan and } \\
\text { 5-FU vs. 5-FU }\end{array}$ & Germany \\
\hline 3 & NCT02170090 & Resected BTCs & 1 st & $\begin{array}{l}\text { Adjuvant GEMCIS vs. } \\
\text { capecitabine }\end{array}$ & Europe, Australia \\
\hline 2 & NCT04466891 & $\begin{array}{l}\text { Locally advanced } \\
\text { HER2-amplified BTCs }\end{array}$ & 2nd & $\begin{array}{l}\text { Zanidatamab, a } \\
\text { HER2-targeted bispecific } \\
\text { antibody }\end{array}$ & $\begin{array}{l}\text { United States, } \\
\text { Europe, Asia }\end{array}$ \\
\hline $2 / 3$ & NCT04066491 & Locally advanced BTCs & 1 st & $\begin{array}{l}\text { bintrafusp alfa with GEMCIS } \\
\text { vs. GEMCIS }\end{array}$ & $\begin{array}{l}\text { United States, } \\
\text { South America, } \\
\text { Australia, Asia, } \\
\text { Europe }\end{array}$ \\
\hline 3 & NCT03779035 & Resected BTCs & 1 st & $\begin{array}{l}\text { Adjuvant GEMCIS vs. } \\
\text { capecitabine }\end{array}$ & China \\
\hline $1 / 2$ & NCT04203160 & Locally advanced BTCs & 1st & $\begin{array}{l}\text { Devimistat, } \\
\text { anti-mitochondrial inhibitor, } \\
\text { with GEMCIS vs. GEMCIS }\end{array}$ & United States \\
\hline 2 & NCT04308174 & BTCs & 1 st & $\begin{array}{l}\text { Neoadjuvant durvalumab } \\
\text { with GEMCIS vs. neoadjuvant } \\
\text { GEMCIS }\end{array}$ & Korea \\
\hline 2 & NCT02151084 & $\begin{array}{l}\text { Locally advanced or } \\
\text { metastatic BTCs }\end{array}$ & 1 st & $\begin{array}{l}\text { Selumetinib with GEMCIS vs. } \\
\text { GEMCIS }\end{array}$ & Canada \\
\hline 2 & NCT02834013 & $\begin{array}{l}\text { Locally advanced } \\
\text { gallbladder cancers }\end{array}$ & 2nd & Nivolumab and ipilimumab & United States \\
\hline
\end{tabular}


Table 3. Cont.

\begin{tabular}{|c|c|c|c|c|c|}
\hline Phase & NCT Number & Tumor Type & Line & Treatment & Location \\
\hline 2 & NCT03260712 & $\begin{array}{l}\text { Locally advanced or } \\
\text { metastatic BTCs }\end{array}$ & 1 st & Pembrolizumab with GEMCIS & Europe \\
\hline 2 & NCT03801083 & $\begin{array}{l}\text { Locally advanced or } \\
\text { metastatic BTCs }\end{array}$ & $\begin{array}{l}\text { 1st and } \\
\text { 2nd }\end{array}$ & $\begin{array}{l}\text { Tumor infiltrating } \\
\text { lymphocytes and IL-2 }\end{array}$ & United States \\
\hline $1 / 2$ & NCT03733990 & $\begin{array}{l}\text { Locally advanced or } \\
\text { metastatic BTCs, } \\
\text { melanoma, ER+ breast, } \\
\text { gastric, ovarian, } \\
\text { pancreatic, colorectal, liver } \\
\text { or anaplastic } \\
\text { thyroid cancers }\end{array}$ & 2nd & $\begin{array}{l}\text { FP-1305, a CLEVER-1 } \\
\text { inhibitor }\end{array}$ & $\begin{array}{l}\text { United States, } \\
\text { Europe }\end{array}$ \\
\hline 2 & NCT04856761 & Resected BTCs & 1 st & $\begin{array}{l}\text { Adjuvant capecitabine vs. } \\
\text { adjuvant S1 }\end{array}$ & China \\
\hline 1 & NCT04495296 & Metastatic solid tumors & 2nd & $\begin{array}{l}\text { TST001, an anti-Claudin } 18.2 \\
\text { monoclonal antibody }\end{array}$ & China \\
\hline 2 & NCT03796429 & Locally advanced BTCs & 1 st & Toripalimab with GEMCIS & China \\
\hline 2 & NCT04059562 & $\begin{array}{l}\text { Locally advanced or } \\
\text { metastatic BTCs }\end{array}$ & 2nd & $\begin{array}{l}\text { Trifluridine/tipiracil with } \\
\text { irinotecan }\end{array}$ & Germany \\
\hline 2 & NCT04969887 & $\begin{array}{l}\text { Intrahepatic } \\
\text { cholangiocarcinomas and } \\
\text { gallbladder cancers }\end{array}$ & $\begin{array}{l}\text { 1st and } \\
\text { 2nd }\end{array}$ & Ipilimumab and nivolumab & Australia \\
\hline $1 / 2$ & NCT05000294 & Metastatic BTCs & 2nd & Atezolizumab with tivozanib & United States \\
\hline 2 & NCT03278106 & Advanced BTCs & 2nd & Trifluridine/tipiracil & United States \\
\hline 3 & NCT03768414 & $\begin{array}{l}\text { Metastatic or locally } \\
\text { advanced BTCs }\end{array}$ & 1 st & $\begin{array}{l}\text { GEMCIS vs. GEMCIS with } \\
\text { nab-paclitaxel }\end{array}$ & United States \\
\hline $1 / 2$ & NCT04742959 & Metastatic BTCs & 2nd & $\begin{array}{l}\text { TT-00420, a } \\
\text { spectrum-selective } \\
\text { multi-kinase inhibitor }\end{array}$ & United States \\
\hline 2 & NCT04383210 & $\begin{array}{l}\text { NRG1 gene fusion } \\
\text { positive advanced BTCs }\end{array}$ & $\begin{array}{l}\text { 1st and } \\
\text { 2nd }\end{array}$ & $\begin{array}{l}\text { Seribantumab, an anti-Her3 } \\
\text { monoclonal antibody }\end{array}$ & United States \\
\hline $1 / 2$ & NCT04426669 & $\begin{array}{l}\text { Metastatic gastrointestinal } \\
\text { epithelial cancers }\end{array}$ & 2nd & $\begin{array}{l}\text { CISH inactivated tumor } \\
\text { infiltrating lymphocytes and } \\
\text { IL-2 }\end{array}$ & United States \\
\hline 2 & NCT04941287 & Unresectable BTCs & 2nd & $\begin{array}{l}\text { Atezolizumab with } \\
\text { varlilumab, an anti-CD27 } \\
\text { antibody vs. atezolizumab } \\
\text { with varlilumab and } \\
\text { cobimetinib }\end{array}$ & United States \\
\hline $1 / 2$ & NCT05086692 & Advanced solid tumors & Any & MDNA11, an engineered IL-2 & Australia \\
\hline $1 / 2$ & NCT04430738 & HER2-positive GI cancers & 1 st & $\begin{array}{l}\text { Tucatinib with trastuzumab } \\
\text { and FOLFOX vs. tucatinib } \\
\text { with trastuzumab and } \\
\text { CAPOX }\end{array}$ & United States \\
\hline 3 & $\begin{array}{l}\text { NCT04924062 and } \\
\text { NCT04924062 }\end{array}$ & $\begin{array}{l}\text { Advanced or unresectable } \\
\text { BTCs }\end{array}$ & 1 st & $\begin{array}{l}\text { Pembrolizumab with GEMCIS } \\
\text { vs. GEMCIS }\end{array}$ & Global \\
\hline 2 & NCT04211168 & Advanced BTCs & 2nd & Toripalimab with lenvatinib & China \\
\hline 2 & NCT02703714 & Advanced BTCs & Any & Pembrolizumab with G-CSF & United States \\
\hline
\end{tabular}


Table 3. Cont.

\begin{tabular}{llllll}
\hline Phase & NCT Number & Tumor Type & Line & Treatment & Location \\
\hline 1 & NCT03985072 & Advanced solid tumors & 2nd & $\begin{array}{l}\text { ANDES-1537, an antisense } \\
\text { oligonucleotide }\end{array}$ & Chile \\
\hline 1 & NCT04853017 & $\begin{array}{l}\text { KRAS mutated } \\
\text { solid tumor }\end{array}$ & Any & $\begin{array}{l}\text { ELI-002 2P, mix of modified } \\
\text { KRAS peptides }\end{array}$ & United States \\
\hline $1 / 2$ & NCT04068194 & $\begin{array}{l}\text { Advanced or metastatic } \\
\text { Hepatobiliary } \\
\text { malignancies }\end{array}$ & 2nd & $\begin{array}{l}\text { RT with avelumab vs. RT with } \\
\text { avelumab and peposertib, a } \\
\text { DNA-PK inhibitor }\end{array}$ & United States \\
\hline 2 & NCT02520141 & $\begin{array}{l}\text { Locally advanced or } \\
\text { metastatic BTCs }\end{array}$ & 2nd & Ramucirumab & United States \\
\hline 1 & NCT02495896 & Advanced solid tumors & Any & $\begin{array}{l}\text { sEphB4-HSA fusion protein } \\
\text { with gemcitabine and } \\
\text { nab-paclitaxel vs. } \\
\text { sEphB4-HSA fusion protein } \\
\text { with docetaxel vs. } \\
\text { sEphB4-HSA fusion protein } \\
\text { with GEMCIS }\end{array}$ \\
\hline
\end{tabular}

\section{Conclusions}

Genomic studies have clearly shown that BTCs are a heterogeneous group of cancers biologically and that cholangiocarcinomas and GBC have distinct genetic alterations. In recent years, more and more actionable mutations are being treated for BTCs as a group, but success in GBC remains limited, as clearly discerned by subgroup analysis of these clinical trials. As of now, in the year 2022, combination chemotherapies continue to be the backbone of treatment for most patients in the frontline, second line, and adjuvant settings. The promising response rate and survival data reported from the phase II study employing GEMCIS plus nab-paclitaxel suggest that imposing extensive DNA damage in GBC cancer cells is a feasible strategy [56]. However, systemic toxicities and durability of this strategy are major concerns. Therefore, understanding the mechanisms of resistance to these regimens and developing novel therapeutic combinations to overcome these mechanisms are critical and most likely to make the largest impact for GBC patients. Another important consideration other than the intrinsic genomic alteration of GBC is the ethnicity of the patient as a biological variable that could potentially impact the natural course and treatment response, as discerned from the TOPAZ-1 study. The molecular underpinnings of this difference remain poorly understood and require intensive research in order to aid patient selection in future clinical trials. The development of robust, dedicated preclinical models such as patient-derived xenografts from different ethnic backgrounds and gender, as well as new genetic mouse models to study GBC as a separate disease, are critically needed to develop novel therapeutic strategies that can be further tested in clinical trials. In the meantime, we should also be acutely aware that BTC is an overall rare cancer, and further dissecting it into different histologic and molecular subgroups, including GBC on its own as separate clinical trials, will be challenging. Thus far, all the seminal trials in BTCs have resulted from close international collaborations, which will remain the bedrock for future efforts in this disease. In summary, GBC is a biologically distinct, rare entity within the spectrum of BTCs with limited treatment options and thus requires intensive and collaborative preclinical and clinical efforts to improve its outcome.

Author Contributions: Z.I.H. and K.-H.L. contributed to the concepts, performed literature review, drafted the manuscript, and approved the submitted version. Z.I.H. drew the figures. All authors have read and agreed to the published version of the manuscript.

Funding: K.-H.L. was supported by NIH/NCI R37CA219697-01, WUSTL SPORE Career Enhancement Award Grant (1P50CA196510-01A1), the American Cancer Society (RSG-17-203-01-TBG), and 
the Alvin J. Siteman Cancer Center Siteman Investment Program (supported by Barnard Trust and The Foundation for Barnes-Jewish Hospital).

Conflicts of Interest: The authors declare no conflict of interest.

\section{References}

1. Han, D.; Yang, J.; Xu, F.; Huang, Q.; Bai, L.; Wei, Y.L.; Kaaya, R.E.; Wang, S.; Lyu, J. Prognostic factors in patients with gallbladder adenocarcinoma identified using competing-risks analysis: A study of cases in the SEER database. Medicine 2020,99, e21322. [CrossRef]

2. Siegel, R.L.; Miller, K.D.; Fuchs, H.E.; Jemal, A. Cancer statistics, 2022. CA Cancer J. Clin. 2022, 72, 7-33. [CrossRef]

3. Ellington, T.D.; Momin, B.; Wilson, R.J.; Henley, S.J.; Wu, M.; Ryerson, A.B. Incidence and Mortality of Cancers of the Biliary Tract, Gallbladder, and Liver by Sex, Age, Race/Ethnicity, and Stage at Diagnosis: United States, 2013 to 2017. Cancer Epidemiol. Biomarkers Prev. 2021, 30, 1607-1614. [CrossRef] [PubMed]

4. Van Dyke, A.L.; Shiels, M.S.; Jones, G.S.; Pfeiffer, R.M.; Petrick, J.L.; Beebe-Dimmer, J.L.; Koshiol, J. Biliary tract cancer incidence and trends in the United States by demographic group, 1999-2013. Cancer 2019, 125, 1489-1498. [CrossRef] [PubMed]

5. Hsing, A.W.; Gao, Y.T.; Han, T.Q.; Rashid, A.; Sakoda, L.C.; Wang, B.S.; Shen, M.C.; Zhang, B.H.; Niwa, S.; Chen, J.; et al. Gallstones and the risk of biliary tract cancer: A population-based study in China. Br. J. Cancer 2007, 97, 1577-1582. [CrossRef] [PubMed]

6. Huang, D.; Joo, H.; Song, N.; Cho, S.; Kim, W.; Shin, A. Association between gallstones and the risk of biliary tract cancer: A systematic review and meta-analysis. Epidemiol. Health 2021, 43, e2021011. [CrossRef] [PubMed]

7. Paraskevopoulos, J.A.; Dennison, A.R.; Ross, B.; Johnson, A.G. Primary carcinoma of the gallbladder: A 10-year experience. Ann. R. Coll. Surg. Engl. 1992, 74, 222-224.

8. Lowenfels, A.B.; Lindstrom, C.G.; Conway, M.J.; Hastings, P.R. Gallstones and risk of gallbladder cancer. J. Natl. Cancer Inst. 1985, $75,77-80$.

9. Muszynska, C.; Lundgren, L.; Lindell, G.; Andersson, R.; Nilsson, J.; Sandstrom, P.; Andersson, B. Predictors of incidental gallbladder cancer in patients undergoing cholecystectomy for benign gallbladder disease: Results from a population-based gallstone surgery registry. Surgery 2017, 162, 256-263. [CrossRef]

10. Duffy, A.; Capanu, M.; Abou-Alfa, G.K.; Huitzil, D.; Jarnagin, W.; Fong, Y.; D’Angelica, M.; Dematteo, R.P.; Blumgart, L.H.; O’Reilly, E.M. Gallbladder cancer (GBC): 10-year experience at Memorial Sloan-Kettering Cancer Centre (MSKCC). J. Surg. Oncol. 2008, 98, 485-489. [CrossRef]

11. Rahman, R.; Simoes, E.J.; Schmaltz, C.; Jackson, C.S.; Ibdah, J.A. Trend analysis and survival of primary gallbladder cancer in the United States: A 1973-2009 population-based study. Cancer Med. 2017, 6, 874-880. [CrossRef]

12. Rawla, P.; Sunkara, T.; Thandra, K.C.; Barsouk, A. Epidemiology of gallbladder cancer. Clin. Exp. Hepatol. 2019, 5, 93-102. [CrossRef]

13. Calle, E.E.; Rodriguez, C.; Walker-Thurmond, K.; Thun, M.J. Overweight, obesity, and mortality from cancer in a prospectively studied cohort of U.S. adults. N. Engl. J. Med. 2003, 348, 1625-1638. [CrossRef]

14. Engeland, A.; Tretli, S.; Austad, G.; Bjorge, T. Height and body mass index in relation to colorectal and gallbladder cancer in two million Norwegian men and women. Cancer Causes Control 2005, 16, 987-996. [CrossRef]

15. Goldberg, M.S.; Theriault, G. Retrospective cohort study of workers of a synthetic textiles plant in Quebec: I. General mortality. Am. J. Ind. Med. 1994, 25, 889-907. [CrossRef]

16. Onyije, F.M.; Hosseini, B.; Togawa, K.; Schuz, J.; Olsson, A. Cancer Incidence and Mortality among Petroleum Industry Workers and Residents Living in Oil Producing Communities: A Systematic Review and Meta-Analysis. Int. J. Environ. Res. Public Health 2021, 18, 4343. [CrossRef]

17. Malker, H.S.; McLaughlin, J.K.; Malker, B.K.; Stone, B.J.; Weiner, J.A.; Ericsson, J.L.; Blot, W.J. Biliary tract cancer and occupation in Sweden. Br. J. Ind. Med. 1986, 43, 257-262. [CrossRef]

18. Dutta, U.; Garg, P.K.; Kumar, R.; Tandon, R.K. Typhoid carriers among patients with gallstones are at increased risk for carcinoma of the gallbladder. Am. J. Gastroenterol. 2000, 95, 784-787. [CrossRef]

19. Nagaraja, V.; Eslick, G.D. Systematic review with meta-analysis: The relationship between chronic Salmonella typhi carrier status and gall-bladder cancer. Aliment. Pharmacol. Ther. 2014, 39, 745-750. [CrossRef]

20. Win, A.K.; Lindor, N.M.; Young, J.P.; Macrae, F.A.; Young, G.P.; Williamson, E.; Parry, S.; Goldblatt, J.; Lipton, L.; Winship, I.; et al. Risks of primary extracolonic cancers following colorectal cancer in lynch syndrome. J. Natl. Cancer Inst. 2012, 104, $1363-1372$. [CrossRef]

21. Espinoza, J.A.; Bizama, C.; Garcia, P.; Ferreccio, C.; Javle, M.; Miquel, J.F.; Koshiol, J.; Roa, J.C. The inflammatory inception of gallbladder cancer. Biochim. Biophys. Acta 2016, 1865, 245-254. [CrossRef]

22. Barreto, S.G.; Dutt, A.; Chaudhary, A. A genetic model for gallbladder carcinogenesis and its dissemination. Ann. Oncol. 2014, 25, 1086-1097. [CrossRef]

23. Roa, I.; de Aretxabala, X.; Araya, J.C.; Roa, J. Preneoplastic lesions in gallbladder cancer. J. Surg. Oncol. 2006, 93, 615-623. [CrossRef] 
24. Roa, I.; Araya, J.C.; Wistuba, I.; Villaseca, M.; de Aretxabala, X.; Busel, D.; Burgos, L. Epithelial lesions associated with gallbladder carcinoma. A methodical study of 32 cases. Rev. Med. Chil. 1993, 121, 21-29.

25. Gonda, T.A.; Tu, S.; Wang, T.C. Chronic inflammation, the tumor microenvironment and carcinogenesis. Cell Cycle 2009, 8, 2005-2013. [CrossRef]

26. Sung, H.; Ferlay, J.; Siegel, R.L.; Laversanne, M.; Soerjomataram, I.; Jemal, A.; Bray, F. Global Cancer Statistics 2020: GLOBOCAN Estimates of Incidence and Mortality Worldwide for 36 Cancers in 185 Countries. CA Cancer J. Clin. 2021, 71, 209-249. [CrossRef] [PubMed]

27. Latorre, S.G.; Ivanovic-Zuvic, S.D.; Corsi, S.O.; Valdivia, C.G.; Margozzini, M.P.; Olea, O.R.; Chianale, B.J.; Miquel, P.J. Coverage of the gallbladder cancer prevention strategy in Chile: Results from the 2009-2010 National Health Survey. Rev. Med. Chil. 2015, 143, 158-167. [CrossRef]

28. Miquel, J.F.; Covarrubias, C.; Villaroel, L.; Mingrone, G.; Greco, A.V.; Puglielli, L.; Carvallo, P.; Marshall, G.; Del Pino, G.; Nervi, F. Genetic epidemiology of cholesterol cholelithiasis among Chilean Hispanics, Amerindians, and Maoris. Gastroenterology 1998, 115, 937-946. [CrossRef]

29. Lorenzo Bermejo, J.; Boekstegers, F.; Gonzalez Silos, R.; Marcelain, K.; Baez Benavides, P.; Barahona Ponce, C.; Muller, B.; Ferreccio, C.; Koshiol, J.; Fischer, C.; et al. Subtypes of Native American ancestry and leading causes of death: Mapuche ancestry-specific associations with gallbladder cancer risk in Chile. PLoS Genet. 2017, 13, e1006756. [CrossRef] [PubMed]

30. Koshiol, J.; Van De Wyngard, V.; McGee, E.E.; Cook, P.; Pfeiffer, R.M.; Mardones, N.; Medina, K.; Olivo, V.; Pettit, K.; Jackson, S.S.; et al. The Chile Biliary Longitudinal Study: A Gallstone Cohort. Am. J. Epidemiol. 2021, 190, 196-206. [CrossRef] [PubMed]

31. Jackson, S.S.; Van De Wyngard, V.; Pfeiffer, R.M.; Cook, P.; Hildesheim, A.; Pinto, L.A.; Jackson, S.H.; Choi, K.; Verdugo, R.A.; Cuevas, M.; et al. Inflammatory profiles in Chilean Mapuche and non-Mapuche women with gallstones at risk of developing gallbladder cancer. Sci. Rep. 2021, 11, 3686. [CrossRef]

32. Elnemr, A.; Ohta, T.; Kayahara, M.; Kitagawa, H.; Yoshimoto, K.; Tani, T.; Shimizu, K.; Nishimura, G.; Terada, T.; Miwa, K. Anomalous pancreaticobiliary ductal junction without bile duct dilatation in gallbladder cancer. Hepatogastroenterology 2001, 48, 382-386.

33. Hu, B.; Gong, B.; Zhou, D.Y. Association of anomalous pancreaticobiliary ductal junction with gallbladder carcinoma in Chinese patients: An ERCP study. Gastrointest. Endosc. 2003, 57, 541-545. [CrossRef]

34. Wang, H.P.; Wu, M.S.; Lin, C.C.; Chang, L.Y.; Kao, A.W.; Wang, H.H.; Lin, J.T. Pancreaticobiliary diseases associated with anomalous pancreaticobiliary ductal union. Gastrointest. Endosc. 1998, 48, 184-189. [CrossRef]

35. Kimura, K.; Ohto, M.; Saisho, H.; Unozawa, T.; Tsuchiya, Y.; Morita, M.; Ebara, M.; Matsutani, S.; Okuda, K. Association of gallbladder carcinoma and anomalous pancreaticobiliary ductal union. Gastroenterology 1985, 89, 1258-1265. [CrossRef]

36. Yoshida, T.; Shibata, K.; Matsumoto, T.; Sasaki, A.; Hirose, R.; Kitano, S. Carcinoma of the gallbladder associated with anomalous junction of the pancreaticobiliary duct in adults. J. Am. Coll. Surg. 1999, 189, 57-62. [CrossRef]

37. Deng, Y.L.; Cheng, N.S.; Lin, Y.X.; Zhou, R.X.; Yang, C.; Jin, Y.W.; Xiong, X.Z. Relationship between pancreaticobiliary maljunction and gallbladder carcinoma: Meta-analysis. Hepatobiliary Pancreat. Dis. Int. 2011, 10, 570-580. [CrossRef]

38. Lamarca, A.; Barriuso, J.; McNamara, M.G.; Valle, J.W. Molecular targeted therapies: Ready for "prime time" in biliary tract cancer. J. Hepatol. 2020, 73, 170-185. [CrossRef]

39. Wu, Y.M.; Su, F.; Kalyana-Sundaram, S.; Khazanov, N.; Ateeq, B.; Cao, X.; Lonigro, R.J.; Vats, P.; Wang, R.; Lin, S.F.; et al. Identification of targetable FGFR gene fusions in diverse cancers. Cancer Discov. 2013, 3, 636-647. [CrossRef]

40. Sia, D.; Losic, B.; Moeini, A.; Cabellos, L.; Hao, K.; Revill, K.; Bonal, D.; Miltiadous, O.; Zhang, Z.; Hoshida, Y.; et al. Massive parallel sequencing uncovers actionable FGFR2-PPHLN1 fusion and ARAF mutations in intrahepatic cholangiocarcinoma. Nat. Commun. 2015, 6, 6087. [CrossRef]

41. Farshidfar, F.; Zheng, S.; Gingras, M.C.; Newton, Y.; Shih, J.; Robertson, A.G.; Hinoue, T.; Hoadley, K.A.; Gibb, E.A.; Roszik, J.; et al. Integrative Genomic Analysis of Cholangiocarcinoma Identifies Distinct IDH-Mutant Molecular Profiles. Cell Rep. 2017, 18, 2780-2794. [CrossRef] [PubMed]

42. Nakamura, H.; Arai, Y.; Totoki, Y.; Shirota, T.; Elzawahry, A.; Kato, M.; Hama, N.; Hosoda, F.; Urushidate, T.; Ohashi, S.; et al. Genomic spectra of biliary tract cancer. Nat. Genet. 2015, 47, 1003-1010. [CrossRef] [PubMed]

43. Roa, I.; de Toro, G.; Schalper, K.; de Aretxabala, X.; Churi, C.; Javle, M. Overexpression of the HER2/neu Gene: A New Therapeutic Possibility for Patients with Advanced Gallbladder Cancer. Gastrointest. Cancer Res. 2014, 7, 42-48. [PubMed]

44. Weinberg, B.A.; Xiu, J.; Lindberg, M.R.; Shields, A.F.; Hwang, J.J.; Poorman, K.; Salem, M.E.; Pishvaian, M.J.; Holcombe, R.F.; Marshall, J.L.; et al. Molecular profiling of biliary cancers reveals distinct molecular alterations and potential therapeutic targets. J. Gastrointest. Oncol. 2019, 10, 652-662. [CrossRef]

45. Javle, M.; Rashid, A.; Churi, C.; Kar, S.; Zuo, M.; Eterovic, A.K.; Nogueras-Gonzalez, G.M.; Janku, F.; Shroff, R.T.; Aloia, T.A.; et al Molecular characterization of gallbladder cancer using somatic mutation profiling. Hum. Pathol. 2014, 45, 701-708. [CrossRef]

46. Jiao, Y.; Pawlik, T.M.; Anders, R.A.; Selaru, F.M.; Streppel, M.M.; Lucas, D.J.; Niknafs, N.; Guthrie, V.B.; Maitra, A.; Argani, P.; et al. Exome sequencing identifies frequent inactivating mutations in BAP1, ARID1A and PBRM1 in intrahepatic cholangiocarcinomas. Nat. Genet. 2013, 45, 1470-1473. [CrossRef]

47. Li, M.; Zhang, Z.; Li, X.; Ye, J.; Wu, X.; Tan, Z.; Liu, C.; Shen, B.; Wang, X.A.; Wu, W.; et al. Whole-exome and targeted gene sequencing of gallbladder carcinoma identifies recurrent mutations in the ErbB pathway. Nat. Genet. 2014, 46, 872-876. [CrossRef] 
48. Narayan, R.R.; Creasy, J.M.; Goldman, D.A.; Gonen, M.; Kandoth, C.; Kundra, R.; Solit, D.B.; Askan, G.; Klimstra, D.S.; Basturk, O.; et al. Regional differences in gallbladder cancer pathogenesis: Insights from a multi-institutional comparison of tumor mutations. Cancer 2019, 125, 575-585. [CrossRef]

49. Vivaldi, C.; Fornaro, L.; Ugolini, C.; Niccoli, C.; Musettini, G.; Pecora, I.; Cacciato Insilla, A.; Salani, F.; Pasquini, G.; Catanese, S.; et al. HER2 Overexpression as a Poor Prognostic Determinant in Resected Biliary Tract Cancer. Oncologist 2020, 25, 886-893. [CrossRef]

50. Hidaka, E.; Yanagisawa, A.; Seki, M.; Takano, K.; Setoguchi, T.; Kato, Y. High frequency of K-ras mutations in biliary duct carcinomas of cases with a long common channel in the papilla of Vater. Cancer Res. 2000, 60, 522-524.

51. Hanada, K.; Tsuchida, A.; Iwao, T.; Eguchi, N.; Sasaki, T.; Morinaka, K.; Matsubara, K.; Kawasaki, Y.; Yamamoto, S.; Kajiyama, G. Gene mutations of K-ras in gallbladder mucosae and gallbladder carcinoma with an anomalous junction of the pancreaticobiliary duct. Am. J. Gastroenterol. 1999, 94, 1638-1642. [CrossRef]

52. Masuhara, S.; Kasuya, K.; Aoki, T.; Yoshimatsu, A.; Tsuchida, A.; Koyanagi, Y. Relation between K-ras codon 12 mutation and p53 protein overexpression in gallbladder cancer and biliary ductal epithelia in patients with pancreaticobiliary maljunction. J. Hepatobiliary Pancreat. Surg. 2000, 7, 198-205. [CrossRef]

53. Wistuba, I.I.; Sugio, K.; Hung, J.; Kishimoto, Y.; Virmani, A.K.; Roa, I.; Albores-Saavedra, J.; Gazdar, A.F. Allele-specific mutations involved in the pathogenesis of endemic gallbladder carcinoma in Chile. Cancer Res. 1995, 55, 2511-2515.

54. Wistuba, I.I.; Gazdar, A.F.; Roa, I.; Albores-Saavedra, J. p53 protein overexpression in gallbladder carcinoma and its precursor lesions: An immunohistochemical study. Hum. Pathol. 1996, 27, 360-365. [CrossRef]

55. Creasy, J.M.; Goldman, D.A.; Dudeja, V.; Lowery, M.; Cercek, A.; Balachandran, V.P.; Allen, P.J.; DeMatteo, R.P.; Kingham, T.P.; D'Angelica, M.I.; et al. Systemic Chemotherapy Combined with Resection for Locally Advanced Gallbladder Carcinoma: Surgical and Survival Outcomes. J. Am. Coll. Surg. 2017, 224, 906-916. [CrossRef]

56. Shroff, R.T.; Javle, M.M.; Xiao, L.; Kaseb, A.O.; Varadhachary, G.R.; Wolff, R.A.; Raghav, K.P.S.; Iwasaki, M.; Masci, P.; Ramanathan, R.K.; et al. Gemcitabine, Cisplatin, and nab-Paclitaxel for the Treatment of Advanced Biliary Tract Cancers: A Phase 2 Clinical Trial. JAMA Oncol. 2019, 5, 824-830. [CrossRef]

57. Jarnagin, W.R.; Ruo, L.; Little, S.A.; Klimstra, D.; D'Angelica, M.; DeMatteo, R.P.; Wagman, R.; Blumgart, L.H.; Fong, Y. Patterns of initial disease recurrence after resection of gallbladder carcinoma and hilar cholangiocarcinoma: Implications for adjuvant therapeutic strategies. Cancer 2003, 98, 1689-1700. [CrossRef]

58. Primrose, J.N.; Fox, R.P.; Palmer, D.H.; Malik, H.Z.; Prasad, R.; Mirza, D.; Anthony, A.; Corrie, P.; Falk, S.; Finch-Jones, M.; et al. Capecitabine compared with observation in resected biliary tract cancer (BILCAP): A randomised, controlled, multicentre, phase 3 study. Lancet Oncol. 2019, 20, 663-673. [CrossRef]

59. Edeline, J.; Benabdelghani, M.; Bertaut, A.; Watelet, J.; Hammel, P.; Joly, J.P.; Boudjema, K.; Fartoux, L.; Bouhier-Leporrier, K.; Jouve, J.L.; et al. Gemcitabine and Oxaliplatin Chemotherapy or Surveillance in Resected Biliary Tract Cancer (PRODIGE 12-ACCORD 18-UNICANCER GI): A Randomized Phase III Study. J. Clin. Oncol. 2019, 37, 658-667. [CrossRef]

60. Ben-Josef, E.; Guthrie, K.A.; El-Khoueiry, A.B.; Corless, C.L.; Zalupski, M.M.; Lowy, A.M.; Thomas, C.R., Jr.; Alberts, S.R.; Dawson, L.A.; Micetich, K.C.; et al. SWOG S0809: A Phase II Intergroup Trial of Adjuvant Capecitabine and Gemcitabine Followed by Radiotherapy and Concurrent Capecitabine in Extrahepatic Cholangiocarcinoma and Gallbladder Carcinoma. J. Clin. Oncol. 2015, 33, 2617-2622. [CrossRef]

61. Valle, J.; Wasan, H.; Palmer, D.H.; Cunningham, D.; Anthoney, A.; Maraveyas, A.; Madhusudan, S.; Iveson, T.; Hughes, S.; Pereira, S.P.; et al. Cisplatin plus gemcitabine versus gemcitabine for biliary tract cancer. N. Engl. J. Med. 2010, 362, 1273-1281. [CrossRef]

62. Lamarca, A.; Palmer, D.H.; Wasan, H.S.; Ross, P.J.; Ma, Y.T.; Arora, A.; Falk, S.; Gillmore, R.; Wadsley, J.; Patel, K.; et al. Second-line FOLFOX chemotherapy versus active symptom control for advanced biliary tract cancer (ABC-06): A phase 3, open-label, randomised, controlled trial. Lancet Oncol. 2021, 22, 690-701. [CrossRef]

63. Yoo, C.; Kim, K.P.; Jeong, J.H.; Kim, I.; Kang, M.J.; Cheon, J.; Kang, B.W.; Ryu, H.; Lee, J.S.; Kim, K.W.; et al. Liposomal irinotecan plus fluorouracil and leucovorin versus fluorouracil and leucovorin for metastatic biliary tract cancer after progression on gemcitabine plus cisplatin (NIFTY): A multicentre, open-label, randomised, phase 2b study. Lancet Oncol. 2021, 22, 1560-1572. [CrossRef]

64. Williams, K.J.; Picus, J.; Trinkhaus, K.; Fournier, C.C.; Suresh, R.; James, J.S.; Tan, B.R. Gemcitabine with carboplatin for advanced biliary tract cancers: A phase II single institution study. HPB 2010, 12, 418-426. [CrossRef]

65. Kim, S.T.; Kang, J.H.; Lee, J.; Lee, H.W.; Oh, S.Y.; Jang, J.S.; Lee, M.A.; Sohn, B.S.; Yoon, S.Y.; Choi, H.J.; et al. Capecitabine plus oxaliplatin versus gemcitabine plus oxaliplatin as first-line therapy for advanced biliary tract cancers: A multicenter, open-label, randomized, phase III, noninferiority trial. Ann. Oncol. 2019, 30, 788-795. [CrossRef]

66. Malka, D.; Cervera, P.; Foulon, S.; Trarbach, T.; de la Fouchardiere, C.; Boucher, E.; Fartoux, L.; Faivre, S.; Blanc, J.F.; Viret, F.; et al. Gemcitabine and oxaliplatin with or without cetuximab in advanced biliary-tract cancer (BINGO): A randomised, open-label, non-comparative phase 2 trial. Lancet Oncol. 2014, 15, 819-828. [CrossRef]

67. Chen, J.S.; Hsu, C.; Chiang, N.J.; Tsai, C.S.; Tsou, H.H.; Huang, S.F.; Bai, L.Y.; Chang, I.C.; Shiah, H.S.; Ho, C.L.; et al. A KRAS mutation status-stratified randomized phase II trial of gemcitabine and oxaliplatin alone or in combination with cetuximab in advanced biliary tract cancer. Ann. Oncol. 2015, 26, 943-949. [CrossRef] 
68. Lubner, S.J.; Mahoney, M.R.; Kolesar, J.L.; Loconte, N.K.; Kim, G.P.; Pitot, H.C.; Philip, P.A.; Picus, J.; Yong, W.P.; Horvath, L.; et al. Report of a multicenter phase II trial testing a combination of biweekly bevacizumab and daily erlotinib in patients with unresectable biliary cancer: A phase II Consortium study. J. Clin. Oncol. 2010, 28, 3491-3497. [CrossRef]

69. Iyer, R.V.; Pokuri, V.K.; Groman, A.; Ma, W.W.; Malhotra, U.; Iancu, D.M.; Grande, C.; Saab, T.B. A Multicenter Phase II Study of Gemcitabine, Capecitabine, and Bevacizumab for Locally Advanced or Metastatic Biliary Tract Cancer. Am. J. Clin. Oncol. 2018, 41, 649-655. [CrossRef]

70. Santoro, A.; Gebbia, V.; Pressiani, T.; Testa, A.; Personeni, N.; Arrivas Bajardi, E.; Foa, P.; Buonadonna, A.; Bencardino, K.; Barone, C.; et al. A randomized, multicenter, phase II study of vandetanib monotherapy versus vandetanib in combination with gemcitabine versus gemcitabine plus placebo in subjects with advanced biliary tract cancer: The VanGogh study. Ann. Oncol. 2015, 26, 542-547. [CrossRef]

71. Makower, D.; Rozenblit, A.; Kaufman, H.; Edelman, M.; Lane, M.E.; Zwiebel, J.; Haynes, H.; Wadler, S. Phase II clinical trial of intralesional administration of the oncolytic adenovirus ONYX-015 in patients with hepatobiliary tumors with correlative p53 studies. Clin. Cancer Res. 2003, 9, 693-702. [PubMed]

72. Peck, J.; Wei, L.; Zalupski, M.; O'Neil, B.; Villalona Calero, M.; Bekaii-Saab, T. HER2/neu may not be an interesting target in biliary cancers: Results of an early phase II study with lapatinib. Oncology 2012, 82, 175-179. [CrossRef]

73. Ramanathan, R.K.; Belani, C.P.; Singh, D.A.; Tanaka, M.; Lenz, H.J.; Yen, Y.; Kindler, H.L.; Iqbal, S.; Longmate, J.; Mack, P.C.; et al. A phase II study of lapatinib in patients with advanced biliary tree and hepatocellular cancer. Cancer Chemother. Pharmacol. 2009, 64, 777-783. [CrossRef] [PubMed]

74. Javle, M.M.; Oh, D.-Y.; Ikeda, M.; Yong, W.-P.; McIntyre, N.; Lindmark, B.; McHale, M. Results from TreeTopp: A randomized phase II study of the efficacy and safety of varlitinib plus capecitabine versus placebo in second-line (2L) advanced or metastatic biliary tract cancer (BTC). J. Clin. Oncol. 2020, 38, 4597. [CrossRef]

75. Javle, M.; Borad, M.J.; Azad, N.S.; Kurzrock, R.; Abou-Alfa, G.K.; George, B.; Hainsworth, J.; Meric-Bernstam, F.; Swanton, C.; Sweeney, C.J.; et al. Pertuzumab and trastuzumab for HER2-positive, metastatic biliary tract cancer (MyPathway): A multicentre, open-label, phase 2a, multiple basket study. Lancet Oncol. 2021, 22, 1290-1300. [CrossRef]

76. Meric-Bernstam, F.; Hanna, D.L.; El-Khoueiry, A.B.; Kang, Y.-K.; Oh, D.-Y.; Chaves, J.M.; Rha, S.Y.; Hamilton, E.P.; Pant, S.; Javle, M.M.; et al. Zanidatamab (ZW25) in HER2-positive biliary tract cancers (BTCs): Results from a phase I study. J. Clin. Oncol. 2021, 39, 299. [CrossRef]

77. Harding, J.J.; Cleary, J.M.; Quinn, D.I.; Braña, I.; Moreno, V.; Borad, M.J.; Loi, S.; Spanggaard, I.; Park, H.; Ford, J.M.; et al. Targeting HER2 (ERBB2) mutation-positive advanced biliary tract cancers with neratinib: Results from the phase II SUMMIT 'basket' trial. J. Clin. Oncol. 2021, 39, 320. [CrossRef]

78. Ohba, A.; Morizane, C.; Ueno, M.; Kobayashi, S.; Kawamoto, Y.; Komatsu, Y.; Ikeda, M.; Sasaki, M.; Okano, N.; Furuse, J.; et al. Multicenter phase II study of trastuzumab deruxtecan (DS-8201) for HER2-positive unresectable or recurrent biliary tract cancer: HERB trial. J. Clin. Oncol. 2020, 38, TPS4654. [CrossRef]

79. Chang, A.E.; Shahda, S.; Harris, W.P.; Cohen, S.; Coveler, A.L.; O’Neil, B.H.; Gadi, V.K.; Hibbert, R.; Lee, H.H.; Younger, A.; et al. Phase I/IB multicenter study of afatinib in combination with capecitabine in patients (pts) with refractory solid tumors and pancreatico-biliary cancers. J. Clin. Oncol. 2017, 35, TPS515. [CrossRef]

80. Javle, M.; Bekaii-Saab, T.; Jain, A.; Wang, Y.; Kelley, R.K.; Wang, K.; Kang, H.C.; Catenacci, D.; Ali, S.; Krishnan, S.; et al. Biliary cancer: Utility of next-generation sequencing for clinical management. Cancer 2016, 122, 3838-3847. [CrossRef]

81. Piha-Paul, S.A.A.; Xu, B.; Janku, F.; Dumbrava, E.E.; Fu, S.; Karp, D.D.; Meric-Bernstam, F.; Hong, D.S.; Ahnert, J.R.; Tsimberidou, A.M.; et al. Phase I study of TT-00420, a multiple kinase inhibitor, as a single agent in advanced solid tumors. J. Clin. Oncol. 2021, 39, 3090. [CrossRef]

82. Goeppert, B.; Frauenschuh, L.; Renner, M.; Roessler, S.; Stenzinger, A.; Klauschen, F.; Warth, A.; Vogel, M.N.; Mehrabi, A.; Hafezi, M.; et al. BRAF V600E-specific immunohistochemistry reveals low mutation rates in biliary tract cancer and restriction to intrahepatic cholangiocarcinoma. Mod. Pathol. 2014, 27, 1028-1034. [CrossRef]

83. Bridgewater, J.; Lopes, A.; Beare, S.; Duggan, M.; Lee, D.; Ricamara, M.; McEntee, D.; Sukumaran, A.; Wasan, H.; Valle, J.W. A phase $1 \mathrm{~b}$ study of Selumetinib in combination with Cisplatin and Gemcitabine in advanced or metastatic biliary tract cancer: The ABC-04 study. BMC Cancer 2016, 16, 153. [CrossRef]

84. Lowery, M.A.; Bradley, M.; Chou, J.F.; Capanu, M.; Gerst, S.; Harding, J.J.; Dika, I.E.; Berger, M.; Zehir, A.; Ptashkin, R.; et al. Binimetinib plus Gemcitabine and Cisplatin Phase I/II Trial in Patients with Advanced Biliary Cancers. Clin. Cancer Res. 2019, 25, 937-945. [CrossRef]

85. Kim, J.W.; Lee, K.H.; Kim, J.W.; Suh, K.J.; Nam, A.R.; Bang, J.H.; Bang, Y.J.; Oh, D.Y. Enhanced antitumor effect of binimetinib in combination with capecitabine for biliary tract cancer patients with mutations in the RAS/RAF/MEK/ERK pathway: Phase Ib study. Br. J. Cancer 2019, 121, 332-339. [CrossRef]

86. Wainberg, Z.A.; Lassen, U.N.; Elez, E.; Italiano, A.; Curigliano, G.; Braud, F.G.D.; Prager, G.; Greil, R.; Stein, A.; Fasolo, A.; et al. Efficacy and safety of dabrafenib (D) and trametinib (T) in patients (pts) with BRAF V600E-mutated biliary tract cancer (BTC): A cohort of the ROAR basket trial. J. Clin. Oncol. 2019, 37, 187. [CrossRef]

87. Subbiah, V.; Lassen, U.; Elez, E.; Italiano, A.; Curigliano, G.; Javle, M.; de Braud, F.; Prager, G.W.; Greil, R.; Stein, A.; et al. Dabrafenib plus trametinib in patients with BRAF(V600E)-mutated biliary tract cancer (ROAR): A phase 2, open-label, single-arm, multicentre basket trial. Lancet Oncol. 2020, 21, 1234-1243. [CrossRef] 
88. Rashid, A.; Ueki, T.; Gao, Y.T.; Houlihan, P.S.; Wallace, C.; Wang, B.S.; Shen, M.C.; Deng, J.; Hsing, A.W. K-ras mutation, p53 overexpression, and microsatellite instability in biliary tract cancers: A population-based study in China. Clin. Cancer Res. 2002, 8, 3156-3163.

89. Piha-Paul, S.A.; Oh, D.Y.; Ueno, M.; Malka, D.; Chung, H.C.; Nagrial, A.; Kelley, R.K.; Ros, W.; Italiano, A.; Nakagawa, K.; et al. Efficacy and safety of pembrolizumab for the treatment of advanced biliary cancer: Results from the KEYNOTE-158 and KEYNOTE-028 studies. Int. J. Cancer 2020, 147, 2190-2198. [CrossRef]

90. Kim, R.D.; Chung, V.; Alese, O.B.; El-Rayes, B.F.; Li, D.; Al-Toubah, T.E.; Schell, M.J.; Zhou, J.M.; Mahipal, A.; Kim, B.H.; et al. A Phase 2 Multi-institutional Study of Nivolumab for Patients with Advanced Refractory Biliary Tract Cancer. JAMA Oncol. 2020, 6, 888-894. [CrossRef]

91. Oh, D.Y.; Chen, L.T.; He, A.R.; Okusaka, T.; Qin, S.; Chin, S.; Rokutanda, N.; Uchinda, H.; Vogel, A.; Valle, J.W.; et al. A phase III, randomized, double-blind, placebo-controlled, international study of durvalumab in combination with gemcitabine plus cisplatin for patients with advanced biliary tract cancers: TOPAZ-1. Ann. Oncol. 2019, 30, 319. [CrossRef]

92. Oh, D.-Y.; He, A.R.; Qin, S.; Chen, L.-T.; Okusaka, T.; Vogel, A.; Kim, J.W.; Suksombooncharoen, T.; Lee, M.A.; Kitano, M.; et al. A phase 3 randomized, double-blind, placebo-controlled study of durvalumab in combination with gemcitabine plus cisplatin (GemCis) in patients (pts) with advanced biliary tract cancer (BTC): TOPAZ-1. J. Clin. Oncol. 2022, 40, 378. [CrossRef] 